\title{
Report of an International Partnership to Develop a New Entry-level Program and Collaborative Research Agendas (Occupational Therapy) between Poland and the US
}

In 2009, the government of Poland to committed to undertake the development of the first four educational programs for occupational therapy in Poland in collaboration with the support from European Network of Occupational Therapy in Higher Education (ENOTHE; www.eu.enothe). This was a significant undertaking in terms of faculty development and curriculum conceptualization designed to meet the unique educational, health and economic context in Poland that had significant need for occupational therapy practitioners in the county to meet the health needs of their citizens particularly related to quality of life in relation to chronic disease and disability to ensure productive childhood and aging.

This report the collaborative educational program development effort between one of the four selected universities, the Józef Piłsudski University of Physical Education in Warsaw (UPE-W) and the European Network of Occupational Therapy in Higher Education (ENOTHE; www.eu.enothe). The background that led to this collaboration is outlined including the drivers for the preparation of qualified faculty with occupational therapy background. The ENOTHE Practicum Objective was created to have at least one lead faculty from each of the Polish universities complete an educational practicum. In this case study, the visiting faculty member chose to come to the United States to complete a combined practica that would support entry-level curricular development and assist the newly trained faculty to engage in occupational therapy research as required by the academic institution and necessary for the development of occupational therapy within the Polish environment. The practica faculty provides the rationale for designing this practica and its outcomes to gather knowledge from a renown curriculum that specializes in developing practice-scholars at Duquesne University and a benchmark research faculty and agenda at University of Illinois at Chicago, both also selected because of individuals engaged in international leadership activities. Like the practica, the Capstone Conference is described as a model to further the international exchange. The value of having the experienced international faculty consult onsite with UPE-W academic leadership and faculty provided expanded understanding and strategic conferencing between UPE-W and visiting faculty regarding curriculum development and development of scholarly agenda, individually and collaboratively.

\section{Introduction}

The formation of the European Union (EU; ec.europa. eu) has proactively impacted occupational therapy practice and education opportunities which can serve as an exemplar for partnerships to expand the profession into new geographical regions where the profession is little known. In 1995, with financial support from the EU ERASMUS initiative, the Council of Occupational Therapists for the European Countries (COTEC) created the European Network of Occupational Therapy in Higher Education (ENOTHE; www.eu.enothe). ENOTHE is a thematic network funded by the European Commission: Socrates Erasmus Program, since 1997 to:
- To unite the European Occupational Therapy Educational Programs and proposed Programs (Institutes, Schools, Universities etc.) in order to advance the education and the body of knowledge of occupational therapy

- To work with COTEC(http://www.cotec-europe.org) to promote occupational therapy education in Europe (www.enothe.eu, retrieved May 17, 2012

One objective of ENOTHE is to provide assistance to institutions who wish to start occupational therapy education programs (e.g. Central and Eastern European Regions) and to advise on potential resources. To date, ENOTHE has facilitated 10 countries with stashing occupational therapy education with another thirteen in 
various stages of development (Personal communication: Gitte Mathiasson ENOTHE Coordinator may 31, 2012).

The Polish government, after joining the EU in 2004, implemented policy and development activities related to EU education planning. While physical therapy education had a long history of presence in the country's universities like many others in Europe, occupational therapy in Poland did not have academic programs comparable to EU members. At this time, Polish occupational therapy practitioners are trained post-high school in trade schools and do not have academic degrees in higher education. Further, other professionals without formal academic preparation in occupational therapy declare that they offer occupational therapy services and/or do applied research. In order for the academic programs in occupational therapy to be delivered within universities, the Polish government requires that faculty qualified to teach occupational therapy be present as well as be able to engage in scholarly activities appropriate to their academic setting. Thus, the existing context prevented occupational therapy education In Poland that ENOTHE could transform.

In 2009, ENOTHE, with support through the European Social Fund, initiated a structured curriculum, the ENOTHE Polish Teacher Training Programme in $O T$, to prepare 32 current academic faculties in four Polish universities with the country's requisite content qualifications to teach occupational therapy with the goal to open bachelor-degree educational programs. One of two capstone events funded representative faculty at each of the universities in Poland to participate in a structured, 3-week placement (practicum) abroad with the goal to observe and understand how occupational therapy is taught and practiced in other countries in order to compare with the Polish situation. The second capstone event, an invited, international symposium, sponsored by Human Capital Programme (European Funds) brought together faculty from ENOTHE, the four Polish universities and the sponsors of the practicum abroad placements to share best practices and scientific evidence focused on promoting the future development of occupational therapy in Poland. Early in discussions to initiate the practicum agreement, faculty at both the Polish and U.S. universities extended the conversation to also include exploration of a long-term, international academic partnership to support cross-cultural engagement between university faculty for instructional and practice scholarship purposes [1]. To deepen the international partnership, a visiting faculty exchange sponsored by the Academy in Warsaw was coupled with the capstone symposium to deepen the international understanding of academic and practice in both contexts which facilitated additional, innovative thinking regarding expanded, mutually-beneficial, international partnership opportunities.
The purpose of this report is to describe the international partnership evolving between two universities to mutually benefit the instructional and scholarly activities reflecting the expectations of an established academic program in synergy with an evolving program in an underserved country. The ENOTHE-facilitated capstone practicum placement initiated between J. Pilsudski University of Physical Education in Warsaw, Poland, and Duquesne University in Pittsburgh, PA, assisted by the University of Illinois at Chicago. The exchange process deepened understanding of each other's academic and practice contexts and motivations that laid the foundation for expanding the partnership beyond original intent. This case study brief will relate the objectives, current activities and plans to solidify this dynamic international partnership beyond occupational therapy curriculum development in Poland. While a case study is typically retrospective for modeling purposes, this one has a prospective element outlining emerging partnership possibilities for both education and practice.

\section{Background}

The advent of the European Union (EU; ec.europa.eu) joined six post -WWII countries with roots back to 1952 , in a distinctive political and economic partnership cross Europe that has impacted occupational therapy practice and education opportunities focused on multiple entities for 27 member countries, that has delivered over half a century of peace, stability, and prosperity in order to help raise living standards. With the launch of a single European currency, the euro in 2001, new efficiencies and inter-country collaborations were enhanced. The most recent ten countries admitted to the EU occurred in 2004 and included Poland. Further, in 2009, the EU country boundaries became further permeable to movement of people and economic resources under one treaty to promote the EU's core values: human dignity, freedom, democracy, equality, and the rule of law.

"Education, Training, Youth" is among one of the multiple areas of EU policy and activity development identified as essential to building a dynamic future across the member countries to develop as a knowledge society and for global economic competitiveness.

Education policy as such is decided by each EU country, but together they set joint goals and share best practices. The EU funds programs that help citizens make the most of their personal development and the EU's economic potential by studying, training or doing volunteer work in other countries.

Within this policy area is the EU's flagship education and training program enabling students to study and work outside their home country each year. In addition, it funds cooperation between higher education institutions across Europe. 
One objective of the European Network of Occupational Therapy in Higher Education (ENOTHE; www.eu.enothe) sponsored by the Council of Occupational Therapists for the European Countries (COTEC) is to provide assistance to institutions who wish to start occupational therapy education programs (e.g. Central and Eastern European Regions) and to advise on potential resources. These educational programs are to reflect the European standards of occupational therapy education in higher education as well as the World Federation of Occupation Therapy (WFOT) standards and quality assurance methods.

In response to the Bologna Declaration of June 1999, ENOTHE initiated the Tuning Project, to establish by 2010 a coherent, compatible and competitive European Higher Education Area, attractive for European students and for students and scholars from other continents. Among many OT Tuning activities, one outcome was the inception of a model for new programs development using an agreed upon comparable set of degrees, credit systems and competencies to facilitate the richness of the European education system while allowing for the independence of local and national academic authorities. Thus, the groundwork was laid for ENOTHE to provide programs and consultation depending on the specific needs and interest of countries desiring to meet the EU comparable standards for occupational therapy education. For Poland, The ENOTHE project established a consortium to provide a strong impetus to set up Occupational Therapy education, practice and research in Poland, compatible with European and World Federation standards. Staff training took place through the 12 modules which consisted of intensive courses, practice, seminars, and distance learning.

The two main aims and objectives for this placement were:

1) Getting acquainted with and understanding the OT curriculum of the host institution

2) Getting acquainted with and understanding how the OT practice is connected with the OT Bachelor Program[2]

Polish schools competed for participation in the project among multiple institutions of higher learning, which were interested in leading the study of occupational therapy. After much consensus, four universities agreed to take part in the projects. All of them have experience in conducting studies in physiotherapy. The following universities are involved in the ENOTHE Polish Teacher Training Program in OT: Placement Abroad:

University of Physical Education in Krakow

University of Physical Education in Warsaw

University of Physical Education in Wroclaw

Higher School of Administration in Bielsko-Biala
In March, 2012, the ENOTHE Programme in Poland was completed to prepare faculty as qualified OT faculty[2].

Building on the prior programme background already discussed, each faculty member engaged In extensive classroom and laboratory experiences delivered by ENOTHE faculty. Each ENOTHE practicum faculty from Poland was encouraged to seek-out professionallyrelevant study aboard placements outside Poland that met expectant future activities within the occupational therapy program. As desired through the EU Erasmus initiative, the recommendation from ENOTHE faculty was for practicum faculty to seek this experience within another EU country to support the core values promoting international flow of professionals and resources easily among the EU countries. This case study reports the outcomes of the Dean, also a program chair in rehabilitation psychology (Andrzej Gryglewicz, PhD, Dean of Students Affairs and Chair, Dept. of Rehabilitation Psychology at the J. Pilsudski University of Physical Education in Warsaw, Poland) who chose, instead, to embark on this practicum experience in the United States stating:

My choice of coming to the US had specific reasons. First of all, I got a strong recommendation about Duquesne's program from Alicja Tisera-Gorecka $\mathrm{PhD}$, a Polish trained basic scientist, who has been working for many years as an occupational therapist in Pittsburgh. Secondly, I elected to study at the OT program at DU as I was highly impressed because it combines a high level of research with a superior standard in education. Lastly, I was interested in the research programs specifically at OT for their outstanding program in practice-scholarship and I followed thier recommendation about seeing the program at UIC.

Because of his university context which mandates faculty research and since he likely would be the administrative leader in program development at his University, his practicum objectives included both leadership and faculty development components. Unlike most ENOTHE faculty participants, he was not likely to teach occupational therapy which would have encouraged extensive exposure to practice during this practicum. Instead, he felt his major contribution would be in developing faculty who would provide this instruction and like he, would undertake related research agendas. His specific research agenda was to standardize assessment tools to diagnose need and measure outcomes from occupational therapy that were reliable and valid within the Polish context.

\section{The ENOTHE Practicum Objective:}

The November 10, 2012, ENOTHE practicum publication, identified the following practicum objectives 
to be accomplished during the three-week study abroad for the Polish faculty:

\section{ENOTHE Educational Practicum Outcomes}

The learning outcomes from the educational practicum experience were to:

a) gain knowledge regarding the host's occupational therapy curriculum design and implementation in relation to the EU TUNING methodology and WFOT educational standards

b) identify valid and reliable instructional methods, pertinent student assessment processes and requisite teaching resources for various curriculum content areas

c) critically analyze what could be integrated into one's own teaching and curriculum delivery back in Poland

\section{ENOTHE Clinical Practicum Outcomes}

The learning outcomes from the clinical practicum experiences were to:

a) observe and where appropriate assist with the practice of occupational therapy in various settings

b) study the professional behaviors and communication styles used by occupational therapy practitioners

c) link academic learning and observed practice expectations [2]

These objectives guided the main activities planned for the practicum faculty coming. The plans were also individualized based on the specific needs and aims of the person coming including prior introduction to occupational therapy. For instance, this faculty had previously attended a research symposiums related to the Model of Human Occupation. The host university also added activities to support the development of the OT profession beyond the university-perspective fit within a global perspective that warranted consideration of the US system as well as the EU one.

\section{Delivering an Individualized ENOTHE Practicum}

The ENOTHE goals coupled with the visiting Dean's called for a program that included not only curriculum and clinical familiarity but also meeting his home University's expectations. Early discussions, uncovered that his practicum objectives would be better served by expanding beyond his host, Duquesne University, for two weeks to be followed by a short-stay with the University of Illinois at Chicago which provided experience enrichment from such differing academic contexts. Duquesne University (DU) is a private, faith-based University (Carnegie classification: doctoral, professional dominant; Research University-high research activity) and the University of Illinois at Chicago (UI-C) (Carnegie classification: comprehensive doctoral; Research University-very high research activity) as a two weeks at DU in Pittsburgh, PA, followed by one week at UI-C. These two universities had partnered for over 10 years on promoting the scholarship of practice in occupational therapy which was of high interest to this practicum faculty $[3,4]$. Each approach to the scholarship of practice is different as faculty activities reflect their university context expectations coupled with the gifts of the faculty. DU afforded opportunity to observe a small faculty who balanced teaching and research while study while enhancing their successful practice-scholar initiative which has focused on applied outcomes-based research in occupational therapy [1]. UI-C afforded the opportunity to observe a dichotomous faculty, a research faculty and a clinical teaching faculty. Here, the visiting practicum faculty wanted to learn about the UI-C scholarship of practice model and initiate plans to validate Model of Occupation assessment tools in Poland. The visiting UPE-W faculty created another link while at UIC with a husband (physical therapist)-wife (counselor) team who were trained in Poland, worked in the US for over 20 years, and now planned to return to Poland. As described by him:

Our curriculum in Warsaw would benefit from someone versed in both cultures as practitioners who could contribute to the translation of materials and practices for Polish application but more importantly help with a meaningful research agenda that would further develop the practice of occupational therapy in Poland.

In fall 2012, after over one year planning and coordinating schedules to ensure beneficial practicum outcomes, the extended visit occurred by the dean from Poland. In both sites, a schedule was initiated to overview curriculum development, opportunities to talk with each occupational therapy faculty as well as key adjuncts providing instruction in anatomy, etc. in order to share teaching content, instructional activities and resources followed by an in class observation of lecture and whenever possible, a lab. In addition, meetings with key researchers interested in collaborating were included.

To observe practice, the fieldwork coordinator took the visiting faculty on a series of her current fieldwork site visits with attention to variety of sites such as acute physical rehabilitation, skilled nursing, hands, pediatric rehabilitation and school-based practice. The breadth of experience was agreed upon to provide insight into curriculum development related to practice readiness versus depth in one practice area as was delineated in ENOTHE as needed to appreciate the differing environments for future faculty and curriculum planning more so than gain therapeutic skill in an area. This modification also afforded extended time with the academic fieldwork coordinator to share processes related to the professional development of students transforming classroom to practice competencies and 
appreciate the needs of fieldwork educators as members of the curriculum team.

Additional activities during the extended stay at DU provided a greater understanding of our clinical partners in practice, enrichment of OT curriculum perspectives, exposure to best practices and consideration of occupational therapy certification and promotion. Introductions to the academic departments of speech Language pathology and physical therapy provided differing levels of comparisons. Physical therapy programs are well developed in Poland and produced so many practitioners that many traveled abroad to assume positions. Also, since there is abundance of academic programs and practitioners, some who provide what occupational therapists, do in other parts of the world, strategies to promote OT in Poland along with role delineations between OT and PT were discussed. Speech pathology in Poland is as underdeveloped as OT. So this time was spent learning about speech pathology and its values a team player in OT practice along with overview of curriculum and running an in-house clinic.

Building on a local asset, three OT academic programs within about 3 miles of each other, the practicum faculty spent time with the program director at the University of Pittsburgh (UPITT) in a research intensive academic program associated with a major medical complex (Carnegie Classification: Research Universityvery high research activity). A campus visit with the Chatham University program director, a primarily post-baccalaureate teaching institution introduced through the program at Chatham University, a Carnegieclassified, Master's University (larger program). In all the visiting faculty would see by practicum end, four OT curriculums all implementing the same set of entrylevel education standards but in differing contexts for faculty and outcomes. The UPE-W probably most closely approximates with the UI-C and UPITT environments. With OT in Poland starting at the baccalaureate level to meet WFOT-approved educational standards will require additional adaptation. However, the DU program through its practice-scholar approach demonstrated a dynamic model for developing faculty to apply in Poland within their own research agenda that can promote the validation and growth of OT practice more rapidly than waiting for practitioners in Poland to have sufficient confidence and competence to study practice outcomes.

\section{Individualized Adaptation}

Five major activities where interjected into a packed schedule during the DU visit in consideration of this practicum faculty's future work and the state of development of OT in Poland: scholarly presentations, meetings with adjunct academic leaders and with local Polish experts; exposure to state-of-the-art research facilities in wheeled mobility and rehabilitation technology and US organizations related to practice certification and the profession. The visiting faculty gave three presentations on campus: one provided an overview the state of development of OT in Poland and the curriculum plans to the OT faculty which more effectively used individual meeting time with more explicit resource identification. Another was in response to an invitation from the DU student Pi Theta Epsilon chapter, to present his own research: The Polish high school graduates and their attitudes towards the disabled people and Ethical problems of rehabilitation as seen by the physiotherapists The third was in a class to explain the evolution of OT in the Poland health care system. Second, meetings with deans and directors of educational technology and libraries, etc., overviewed helpful resources in addressing academic issues using web-based communication tools, search engines such as creating OT-specific Pathfinder for location of essential and/or frequently used resources or reference tools. Meetings with the school's student recruiter and academic adviser (general academic management) were held as models to approach these essential activities. Ties with Poland included meetings with the OT from Poland who recommended DU as the practicum site and conversation with a campus faculty who is also the Honorary Consul of the Republic of Poland, Jan Napoleon Saykiewicz, Ph.D. D.Sc. to understand the strong Polish communities within Pittsburgh. The OT was trained in the US after leaving Poland following an extensive laboratory research career and seeks a research partnership with UPE-W.

Every context provides unique learning not to be missed. The University of Pittsburgh Medical Center has the leading wheeled mobility and rehabilitation technology labs in the world. Visits wee planned with the Center for Assistive Technology and the Human Engineering Research Laboratories (http://www.upmc. com/Services/rehab/rehab-institute/services/cat/Pages/ default.aspx and http://www.herl.pitt.edu) . Pittsburgh is located close to Washington DC which afforded a fieldtrip to talk with the National Board of Certification in Occupational therapy (nbcot.org) and the membership organization, the American Occupational therapy Association (aota.org). NBCOT afforded a discussion about entry-level practice competencies $s$ expected in the US. and knowledge regarding the requirements for international students to seek become certified to practice in the US. AOTA provided an overview of their activities and interface with state associations. Most rewarding was the extensive overview of reference material and educational resources that they produce to support practice which will be advantageous during curriculum development and introduction of occupational therapy practice in Poland. 


\section{Capstone Conference and Visit to UPE-W}

The visiting faculty from Duquesne had a twopart visit in winter 2012 that included presenting at the capstone symposium to close the ENOTHE project in Poland in Krakow. An invited address was presented on the development of practice-scholars as well as a pre-symposium workshop on the best practices in fieldwork education. This also afforded opportunity to meet all four university faculties and learn about this plans for programs and related research. For instance, one is working with Canada to validate the Canadian Occupational Performance Measure for the Polish context. Renee Taylor, a collaborator in this project, from UIC, presented a workshop regarding the Model of Human Occupation and the Intentional relationship as well as an invited address regarding the later topic at the symposium.

This capstone symposium provided opportunity to extend into an extended seven-day visit to UPE-W to fully acknowledge this university's context for future collaborative activities. Multiple activities within the university and two visits, one to a public hospital and one to a private one (Medicover), provided discussion, insight and sharing of future goals for occupational therapy education and proactive that could be served by the evolving partnership. A presentation was given to the faculty council and president regarding occupational therapy and how its presence would enhance university activities and productivity as well as potential to significantly address pending health care needs in the country. Visits were made with several department faculties and leadership including key administrators to support the development of the program as well as answer questions. Physical therapy whose supply of graduates exceeds demands in Poland was curious about the interface with occupational therapy and professional boundaries. Additional activities included:

- touring state-of-the-art research labs

outline of a grant to partner on the validation studies

of the Model of Human Occupation Screening Tool

(MOHOST) and the Activity Card Sort (ACL) for use

in Polish service delivery [5] Baum, et.al.[6]

- consideration of writing a partnership grant with one hospital to demonstrate the value of hand-splinting to enhance function with hopes of providing the effectiveness of effectiveness introducing hand splinting to the health care reimbursement system.

- Consultation regarding implementation of the occupational therapy curriculum within the specific context of UPE-W including further conversations with ENOTHE-Trained faculty

- Coaching of a young faculty who wishes to pursue a post-doctoral experience in biomechanics in the U.S.
- Introduction to current Polish occupational therapists who are technically-trained and observation of their practice.

- Exploration of future faculty, student and practitioner exchanges for a variety of activities.

With all presentations, translation was provided. The most beneficial translation was provided by a counselor raised in Poland but who had worked in the U.S for over ten years, The presence of a translator provided ease In providing meaningful communication of information between parties. As part of a planned return to re-locate back to her home country, discussion regarding her future assistance in translating professional resources from English to Polish as well as collaborating on grants and publications was discussed extensively.

\section{Summary and Future Plans}

While the partnership between DU, APE-W and UI-C continues to evolve, even the subtleties enrich the broader outcomes. For instance, the Polish people have hesitation about any profession whose root word is in 'occupy' because of their extended, negative historical experiences wedged between Germany and Russia presents a unique. Like the U.S, Poland is stretching to address quality of life issues for their aging population. But with differing economies, health care and social systems and resource availability, (nationally in US and through the EU for Poland), Poland's expansion of occupational therapy is directly related to the ability to provide added-benefit within the unique health care needs and systems. Promoting as well as documenting the influence of occupational therapy is essential.

Deciding which EU or US variations of practice will translate or be adaptable to Poland's needs is being discovered as this case study is being read. While in Poland in March 2012, the national occupational therapy association for Poland was formed at the capstone symposium. Imagine the task ahead: defining and promoting meaningful OT practice in Poland; considering regulation of practice; leading future directions, ensuring scholarship). Further, through this partnership in this case study, exploration of faculty exchanges, student study aboard and other curriculum interchanges are expedited through the activities presented in this case study.

Certainly, the development of occupational therapy in a nation where none exists or what does exist, is not comparable to international expectations, be it the EU's or WFOT's, Skepticism is strong among developed countries with OT, about the viability of introducing occupational therapy education where no practitioners or education cannot be presented by OTS. However, ENOTHE has enacted a dynamic, successful plan with positive outcomes within the EU for such countries 
that could be modeled work-wide. Further, this case study elucidates the viability of building with the plan, international practica that can provide extended networks engaging others to facilitate this process.

Many opportunities for OTs from other countries to assist with this effort in Poland and other countries without occupational therapy education to provide short and long-term collaborations are available. In a decade, we will look back at this country amazed that a nation who had no formally educated OT faculty could progress to the point of flourishing. Hopefully, pride of of-going and likely expanded international partnerships will be evident. Finally, Poland's evolution of occupational therapy will not only enhance quality of life in Poland for its citizens but also enrich the cross-cultural perspective of the occupational therapy profession.

\section{Acknowledgments:}

The authors would like to especially thank:

United States - Renee Taylor at the University of Illinois-Chicago for her facilitation of the placement on her campus; the Duquesne University OT faculty who shared their curriculum and faculty scholarship freely: Dr. Jaime Muñoz, program director, Jeryl Benson, Elizabeth DeIuliis Kim Szucs and Anne Marie Witchger Hansen, Dr. Joan Rogers at the University of Pittsburgh and Dr. Joyce Salls at Chatham University for over-viewing their curriculums and faculty scholarship; Shaun Conway, Director of Credentialing Services at the National Board for Certification in Occupational Therapy who overviewed entry-level practice standards and current as well as proposed certification requirements for internationally-trained occupational therapists; and Frederick Somers, Executive Director and Maureen Freda Peterson, Chief, Professional Affairs Division Officer at the American Occupational Therapy Association regarding the organization and promotion of occupational therapy practice. Very special thanks Alicja Gorecka-Tisera, PhD, OTR for advocating for the establishment of this partnership between DU and APE-W.

Poland - prof. Alicja Przyłuska-Fiszer - Rector Academy of Physical Education - Warsaw,

Prof. Anna Marchewka - Dean of Faculty of Movement Rehabilitation APE-Krakow Janusz Domaniecki Dean of Faculty of Rehabilitation APE-
Warsaw. Janusz Bromboszcz PhD - international coordinator and initiator of the project. Malgorzata Laskowska - counselor and volunteers who fight against poor, Pawel Laskowski - PT and hand therapist.

ENOTHE: Hanneke van Bruggen, the leading ENOTHE- Poland course supervisor for her discussion in Poland and initial commentary on manuscript concepts

\section{References}

1. Crist PA, Muñoz JP, Hansen AMW, Benson J, Provident I. The Practice-Scholar Program: An academic-practice partnership to promote the scholarship of "best practices." Occup Ther Health Care 2005; 19: 71-93.

2. European Network of Occupational Therapy in Higher Education. (November, 2010). Polish teacher training program in OT: Placement Aboard. European Network of Occupational Therapy in Higher Education: Copenhagen, Denmark.

3. Crist PA, Kielhofner G. (eds.). The scholarship of practice in occupational therapy: Academic-practice collaborations for promoting occupational therapy. New York: Haworth Publications 2005. /Originally published as special edition of Occup Ther Health Care 2005; 19 (1-2)/.

4. Kielhofner G, Fogg L, Braveman B, Forsyth K, Kramer J, Duncan E. A factor analytic study of the Model of Human Occupation Screening Tool of hypothesized variables. Occup Ther Ment Health 2009; 25: 127-137.

5. Baum CM. Edwards D. Activity Card Sort. 2nd ed. Rockville AOTA Press; 2008.

6. Kielhofner G. A scholarship of practice: Creating discourse between theory, research and practice. Occup Ther Health Care 2005; 19: 7-16.

\section{Patricia Crist}

She was associated with Duquesne University, Pittsburgh, PA and the time of this collaboration. She is now Founding Chair at the Nortern Arizona University (Department of Occupational Therapy College of Health and Human Services) Phoenix, USA

\section{Andrzej Gryglewicz}

Faculty of Rehabilitation University of Physical Education Warsaw, Poland 